\title{
Convulsions Induced by 2-N-Di-n-Butylaminoethanol ${ }^{1}$
}

\author{
Rolf Hartung, Lester B. Pittle, and Herbert H. Cornish \\ The University of Michigan School of Public Health, \\ Department of Industrial Health, Ann Arbor, Michigan 48104
}

Received May 28, 1969

\begin{abstract}
Convulsions Induced by $2-N$-Di- $n$-Butylaminoethanol. HARTUNG, RoLF, Pittle, Lester B., and Cornish, Herbert, H. (1970). Toxicol. Appl. Pharmacol. 17, 337-343. Dibutylaminoethanol $\left(\mathrm{Bu}_{2} \mathrm{AE}\right)$ produces convulsions in rats leading to respiratory arrest regardless of route of administration. The lethality of $5 \times \mathrm{LD} 50$ doses of $\mathrm{Bu}_{2} \mathrm{AE}$ can be readily overcome by artificial respiration for 2-4 hr. In vivo phrenic nerve-diaphragm preparations indicate that the respiratory arrest is due to a neuromuscular blockade. Spontaneous activity of the phrenic nerve increases during convulsions and persists during blockade. Pretreatment with mephenesin or diphenylhydantoin, but not pentobarbital, was effective in counteracting convulsions and respiratory arrest. $\mathrm{Bu}_{2} \mathrm{AE}$ has also been shown to be a moderate inhibitor of acetylcholinesterase. It is proposed that the increased nerve activity during convulsions with its simultaneous increase in acetylcholine release, acts in concert with the moderate level of cholinesterase inhibition, producing a neuromuscular blockade due to excessive acetylcholine accumulation at the junction.
\end{abstract}

Dibutylaminoethanol $\left(\mathrm{Bu}_{2} \mathrm{AE}\right)$ has found use as a conditioning agent for cellulose acetate filaments to facilitale textile manufacture, a catalyst in polyurethane foam manufacture, an anticorrosion additive for lubricants and hydraulic fluids, in the manufacture of emulsifying and dispersing agents, and in the curing of silicone resins.

$\mathrm{Bu}_{2} \mathrm{AE}$ has been investigated by us because it is one of the more toxic in a long series of alkyl-substituted aminoethanols. The oral LD50 of this compound has been reported as $1.07 \mathrm{~g} / \mathrm{kg}$ by Smyth et al. (1954). Cornish et al. (1969) found that $\mathrm{Bu}_{2} \mathrm{AE}$ in drinking water at 0.2 and $0.4 \mathrm{~g} / \mathrm{kg}$ per day in rats resulted in reduced body weight and slight increases in kidney weight without accompanying pathology. Inhalation studies at 70 ppm for 6 hr daily for 5 days, resulted in weight losses, chromodacryorrhea, tremors, and some convulsions. At that dose level there was $20 \%$ mortality.

Characteristically $\mathrm{Bu}_{2} \mathrm{AE}$ acts by inducing strong clonic-tonic convulsions which closely resemble a Grand Mal seizure. These convulsions were noted after oral and intraperitoneal administrations as well as inhalation of $\mathrm{Bu}_{2} \mathrm{AE}$. All observed mortalities due to $\mathrm{Bu}_{2} \mathrm{AE}$ were preceded by convulsions. Because of this close relationship, they were studied in greater detail.

\section{METHODS}

There appeared to be no qualitative difference in the convulsions associated with acute or subchronic exposures or with variations in route of administration. Therefore

${ }^{1}$ Presented in part at the 1969 Society of Toxicology meeting, Williamsburg, Virginia. 
the following series of experiments were standardized using ip injections of $\mathrm{Bu}_{2} \mathrm{AE}$. Male Sprague-Dawley rats (Spartan strain) were used throughout.

Like most alkyl-substituted aminoethanols, $\mathrm{Bu}_{2} \mathrm{AE}$ is normally quite alkaline with a $\mathrm{p} K_{a}$ of 9.67 (Gero, 1963). Prior to use, commercial $\mathrm{Bu}_{2} \mathrm{AE}$ (Eastman Organic Chemicals) was further purified by fractional vacuum distillation. It was then neutralized with $\mathrm{HCl}$ to avoid the direct effects of alkalinity. Doses are reported in terms of $\mathrm{Bu}_{2} \mathrm{AE}$ base. Statistical analyses of the ED50 and LD50 data were done using the logistic analysis of Berkson (1944), which we have programmed for computer use. Electroencephalograms were taken under pentobarbital anesthesia between right frontal and right parietal areas with the electrodes directly attached to the skull. In vivo nerve-diaphragm preparations were prepared as illustrated in Fig. 1. Mathematical analysis of nerve activity was done by computer-assisted polynomial regression.

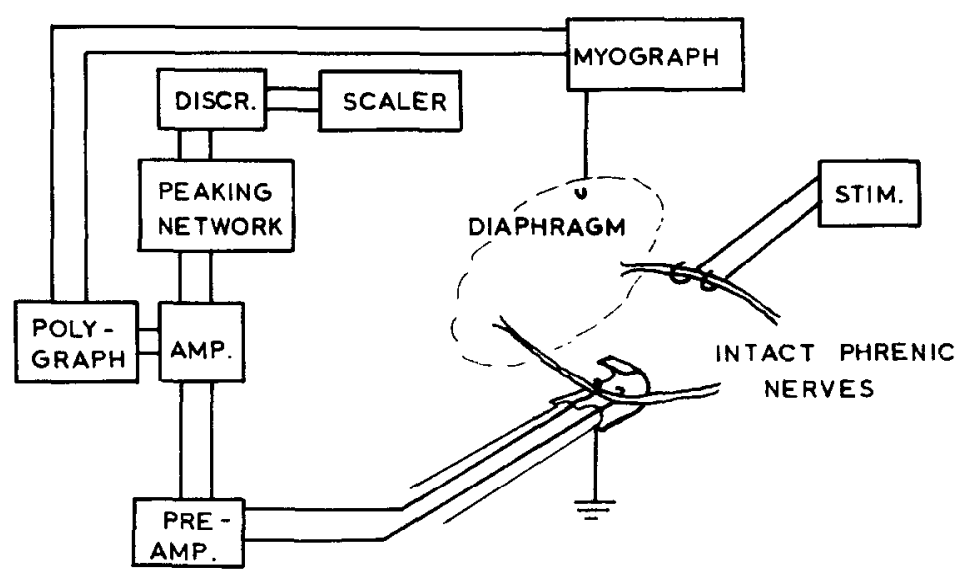

FIG. 1. Experimental configuration for measuring spontaneous phrenic nerve activity and for simultaneous determination of threshold voltage for stimulation of contraction of the rat diaphragm.

\section{RESULTS}

After ip injection the median effective dose for the production of convulsions was $50.6 \mathrm{mg} / \mathrm{kg}$ (95\% fiducial limits: $31.6-80.9$ ), and the LD50 was found to be $89.1 \mathrm{mg} / \mathrm{kg}$ (95\% fiducial limits: 40.6-195.6). There is a significant overlap between convulsive dose and lethal dose. Many of the rats which reached the convulsive stage also died.

Shortly after $\mathrm{Bu}_{2} \mathrm{AE}$ injection, there appears to be an increase in rhythmic electrical activity of the EEG which becomes very pronounced during the ensuing convulsions (Fig. 2). In this case, these convulsions were reduced to very heavy tremors under the influence of the barbiturate anesthesia. During light pentobarbital anesthesia, the rat will frequently wake up after $\mathrm{Bu}_{2} \mathrm{AE}$ and shortly go into frank convulsions. The convulsions then lead to a respiratory arrest and a flattening of the EEG due to anoxia. The convulsions arose centrally as indicated by the EEG and substantiated by the fact that convulsions disappeared distally upon spinal section.

The immediate cause of death after $\mathrm{Bu}_{2} \mathrm{AE}$ appears to be the respiratory arrest which follows immediately after the convulsions. We attempted to counteract the respiratory 
arrest phase by artificial respiration after doses up to $500 \mathrm{mg} / \mathrm{kg}$ ip $\mathrm{Bu}_{2} \mathrm{AE}$. This represents approximately 5-6 LD50. The rats were placed under light pentobarbital anesthesia and respired via a tracheal cannula using a Physiograph respirator. After an initial period of moderate convulsions and tremors, the experimental animals stopped breathing spontaneously, as tested by briefly interrupting the artificial respiration. The animals did not develop cyanosis at any time during this treatment. The artificial respiration counteracted the respiratory failure, but not the convulsions.

After the convulsive phase, the animals appeared to be in a generalized state of flaccid paralysis for 2-4 hr. After these $2-4 \mathrm{hr}$ of artificial respiration, all animals wcre able to resume breathing on their own and were able to walk a short time after that. When function was regained, the signs of tremors and convulsions did not reappear.

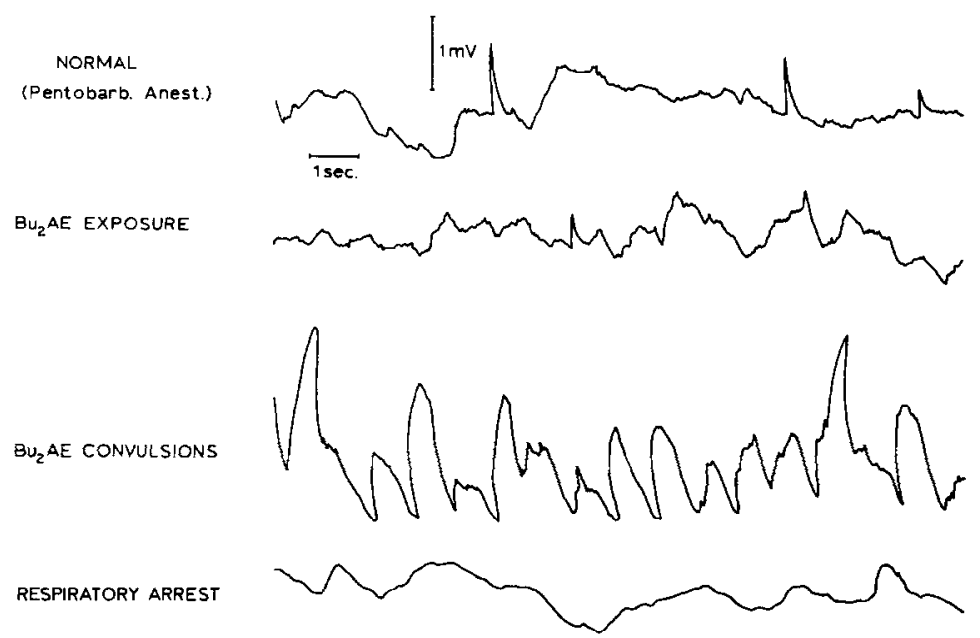

FIG. 2. EEG-right frontal to right parietal; electrodes placed on the surface of the skull in a rat after $250 \mathrm{mg} / \mathrm{kg}$ ip $\mathrm{Bu}_{2} \mathrm{AE}$.

Since artificial respiration was effective in counteracting the lethality of $\mathrm{Bu}_{2} \mathrm{AE}$ due to respiratory arrest without appreciably affecting the convulsions, we investigated the nature of that respiratory arrest. For this investigation, we utilized the in vivo nervediaphragm preparation as illustrated in Fig. 1. We were thus able to measure the spontaneous activity of the intact phrenic nerve, and also were able to study the effect of stimulating the phrenic nerve on the contractility of the rat diaphragm. Stimulating the phrenic nerve indicated that a neuromuscular blockade developed whose onset was dose related (Fig. 3). For individual rats within these groups, the onset of the blockade was typically abrupt. There also was a general indication that the severity of the blockade was dose related.

The recordings of spontaneously occurring nerve activity exhibited a great deal more variability. The basic method of measurement, using a scaler and counting all impulses above a certain threshold voltage, plainly suffered from lack of sophistication and equipment. Nevertheless, the data in Fig. 4 demonstrate that some activity in the intact phrenic nerve persists even during the neuromuscular blockade, and that there is a trend toward higher nerve activity for higher dose levels of $\mathrm{Bu}_{2} \mathrm{AE}$. Much of that increase 
occurs during the convulsive stage and is probably due to the increased central stimulation after $\mathrm{Bu}_{2} \mathrm{AE}$.

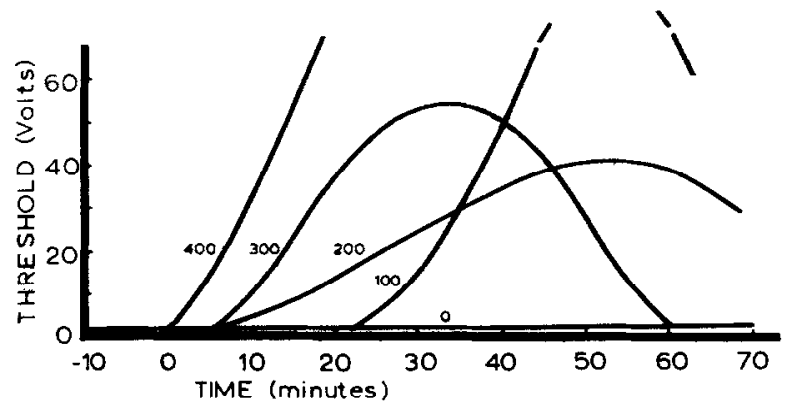

Fig. 3. Polynomial regressions (5th degree) of threshold voltages for phrenic nerve stimulation eliciting contraction of the diaphragm. Time of injection is at $0 \mathrm{~min}$; dosages are indicated as $\mathrm{mg} / \mathrm{kg}$ ip of $\mathrm{Bu}_{2}$ AE. $400 \mathrm{mg} / \mathrm{kg}$ : No. of rats $(\mathrm{NR})=5$, No. of determinations $(\mathrm{ND})=299, F$ value $=72.40 ; 300$ $\mathrm{mg} / \mathrm{kg}: \mathrm{NR}=5, \mathrm{ND}=332, F=23.50 ; 200 \mathrm{mg} / \mathrm{kg}: \mathrm{NR}=8, \mathrm{ND}=500, F=27.15 ; 100 \mathrm{mg} / \mathrm{kg}: \mathrm{NR}=2$, $\mathrm{ND}=137, F=205.53 ; 0 \mathrm{mg} / \mathrm{kg}: \mathrm{NR}=2, \mathrm{ND}=137, F=-$.

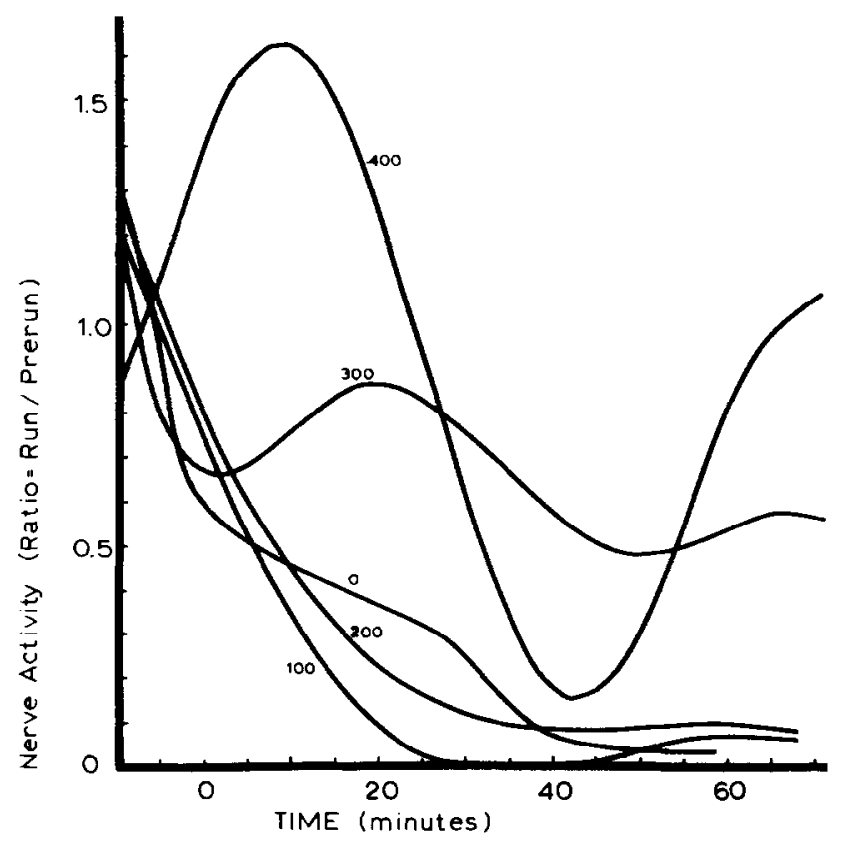

FIG. 4. Polynomial regressions (5th degree) of relative spontaneous phrenic nerve activity. Time of injection is at $0 \mathrm{~min}$, dosages are indicated as $\mathrm{mg} / \mathrm{kg}$ ip of $\mathrm{Bu}_{2} \mathrm{AE} .400 \mathrm{mg} / \mathrm{kg}: \mathrm{NR}=5, \mathrm{ND}=391$, $F=7.01 ; 300 \mathrm{mg} / \mathrm{kg}: \mathrm{NR}=5, \mathrm{ND}=332, F=0.59 ; 200 \mathrm{mg} / \mathrm{kg}: \mathrm{NR}=8, \mathrm{ND}=500, F=21.99$; $100 \mathrm{mg} / \mathrm{kg}: \mathrm{NR}=2, \mathrm{ND}=139, F=38.62 ; 0 \mathrm{mg} / \mathrm{kg}: \mathrm{NR}=2, \mathrm{ND}=78, F=6.98$.

Many of the preceding data of course had to he gathered during artificial respiration. Without artificial respiration or other treatment, the time course of these events is normally quite short. At $250 \mathrm{mg} / \mathrm{kg}$, which represents approximately a $3 \times$ LD50 dose, time to first convulsion was typically $2.9 \pm 0.3$ (mean \pm SE) min and time to death 
TABLE 1

EFFECT OF MEPHENESIN ON Bu $\mathrm{B}_{2}$ AE CONVULSIONS IN RATS

\begin{tabular}{|c|c|c|c|c|c|}
\hline $\begin{array}{l}\text { Pretreatment } \\
\text { Mephenesin } \\
\text { (mg/rat) }\end{array}$ & $\begin{array}{c}\mathrm{Bu}_{2} \mathrm{AE} \\
(\mathrm{mg} / \mathrm{kg})\end{array}$ & $\begin{array}{l}\text { Interval between } \\
\text { treatments } \\
(\mathrm{min})\end{array}$ & $\begin{array}{c}\text { Time to } 1 \mathrm{st} \\
\text { convulsion, } \\
t_{\mathrm{c}} \\
\text { (min) }\end{array}$ & $\begin{array}{c}\text { Time to } \\
\text { death, } \\
t_{\mathrm{d}} \\
\text { (min) }\end{array}$ & Survival \\
\hline $20 \mathrm{iv}$ & 400 & 2.0 & - & - & Survived \\
\hline 20 & 320 & 3.0 & - & - & Survived \\
\hline 20 & 400 & 3.0 & 2.0 & 4.0 & \\
\hline 20 & 400 & 3.0 & 37.0 & - & Survived \\
\hline 20 & 400 & 3.0 & 15.0 & 37.0 & \\
\hline 40 po & 250 & 90 & - & - & Survived \\
\hline 40 & 250 & 90 & 1.8 & 6.2 & \\
\hline 40 & 250 & 90 & - & - & Survived \\
\hline 40 & 250 & 90 & 10.0 & - & Survived \\
\hline 40 & 250 & 90 & 1.0 & 5.5 & \\
\hline 40 & 250 & 90 & 1.8 & 6.0 & \\
\hline 80 po & 250 & 90 & 4.0 & 8.0 & \\
\hline 80 & 250 & 90 & - & - & Survived \\
\hline 80 & 250 & 90 & 1.8 & 5.5 & \\
\hline 80 & 250 & 90 & 1.8 & 8.6 & \\
\hline 80 & 250 & 90 & - & - & Survived \\
\hline 80 & 250 & 90 & 2.2 & 7.8 & \\
\hline 80 & 250 & 45 & 11.5 & - & Survived \\
\hline 80 & 250 & 45 & - & - & Survived \\
\hline 80 & 250 & 45 & 6.5 & - & Survived \\
\hline 80 & 250 & 45 & - & - & Survived \\
\hline 80 & 250 & 45 & 2.5 & 15.8 & \\
\hline 80 & 250 & 30 & - & - & Survived \\
\hline 80 & 250 & 30 & 4.2 & 9.0 & \\
\hline 80 & 250 & 30 & 4.2 & - & Survived \\
\hline 80 & 250 & 31 & - & - & Survived \\
\hline 80 & 250 & 30 & 3.2 & 9.0 & Survived \\
\hline
\end{tabular}

TABLE 2

EFFect of Diphenylhydantoin on $\mathrm{Bu}_{2}$ AE CONVUlsions in RatS

\begin{tabular}{cccccc}
\hline $\begin{array}{c}\text { Pretreatment } \\
\text { diphenyl- } \\
\text { hydantion (iv) } \\
(\mathrm{mg} / \mathrm{kg})\end{array}$ & $\begin{array}{c}\mathrm{Bu}_{2} \mathrm{AE} \\
(\mathrm{mg} / \mathrm{kg})\end{array}$ & $\begin{array}{c}\text { Interval between } \\
\text { treatments } \\
(\mathrm{min})\end{array}$ & $\begin{array}{c}\text { Time to 1st } \\
\text { convulsion, } \\
t_{\mathrm{c}} \\
(\mathrm{min})\end{array}$ & $\begin{array}{c}\text { Time to } \\
\text { death } \\
t_{\mathrm{d}} \\
(\mathrm{min})\end{array}$ & Survival \\
\hline 5 & 250 & 2.0 & - & - & Survived \\
5 & 250 & 2.0 & 2.0 & 7.2 & Survived \\
5 & 250 & 2.0 & - & - & Survived \\
5 & 250 & 1.8 & - & - & Survived \\
5 & 250 & 1.8 & - & - & Survived \\
5 & 250 & 2.0 & - & - & Survived \\
5 & 250 & 2.0 & & & $\mathbf{8 5 . 7 \% )}$ \\
\hline
\end{tabular}


$7.8+1.0 \mathrm{~min}$. Under these conditions, the mortality was $100 \%$ in 10 experiments. The same dose was used in most of the subsequent experiments which tested various $\mathrm{Bu}_{2} \mathrm{AE}$ drug interrelations.

We had previously demonstrated that $\mathrm{Bu}_{2} \mathrm{AE}$ was a moderately active inhibitor of acetylcholinesterase (Hartung and Cornish, 1968). Therefore, we investigated the effect of pretreatment with atropine on $\mathrm{Bu}_{2} \mathrm{AE}$-induced convulsions. The $\mathrm{Bu}_{2} \mathrm{AE}$ was injected when atropinization had been achieved, as judged by pupil size. Dosages of atropine ranging from 0.02 to $0.2 \mathrm{mg} / \mathrm{kg}$ had no significant effect on the time course or the outcome of convulsions and respiratory arrest induced by $\mathrm{Bu}_{2} \mathrm{AE}$ doses as low as 125 $\mathrm{mg} / \mathrm{kg}$. Since atropine is mainly effective in counteracting the parasympathomimetic effects of anticholinesterases, but not neuromuscular effects, these results were not unexpected.

The possibility still remained that this was a curarelike neuromuscular blockade. Therefore we employed $0.85 \mathrm{mg} / \mathrm{kg}$ iv edrophonium, which is a valuable antagonist against some curariform neuromuscular blockers. It too had no effect on the time course or outcome.

Since none of the tested peripherally acting antagonists to neuromuscular blocking agents had been effective in counteracting $\mathrm{Bu}_{2} \mathrm{AE}$ toxicity, we decided to test some of the centrally acting anticonvulsants.

Throughout our work with anesthetized rats we had noted that barbiturates in moderate doses were unable to control $\mathrm{Bu}_{2} \mathrm{AE}$-induced convulsions. Therefore we investigated a series of other anticonvulsants.

Magnesium sulfate $(1 \mathrm{mg} / \mathrm{kg}$ iv) given as pretreatment resulted in 1 survival in 6 . The significance of that effect may be questionable. Higher dose levels may be more effective.

Mephenesin was far more effective as an anticonvulsant against $\mathrm{Bu}_{2} \mathrm{AE}$ (Table 1). In these tests, a curious effect became evident. Animals which did not develop convulsions, survived without developing any indication of respiratory arrest. When the onset of convulsions could be delayed to $6 \mathrm{~min}$, the rats usually survived. In those cases the convulsions were much weaker and alternated with heavy tremors for as long as $1.5 \mathrm{hr}$ without producing a respiratory arrest.

Diphenylhydantoin $\left(5 \mathrm{mg} / \mathrm{kg}\right.$ iv) was the most effective drug for preventing $\mathrm{Bu}_{2} \mathrm{AE}$ induced convulsions (Table 2). It almost completely prevented convulsions and mortalities after normally lethal doses of $\mathrm{Bu}_{2} \mathrm{AE}$.

On the other hand, trimethadione was ineffective in controlling $\mathrm{Bu}_{2} \mathrm{AE}$-induced convulsions even at doses $(150 \mathrm{mg} / \mathrm{kg}$ ip) which had been found effective in counteracting a lethal dose of the convulsant pentylenetetrazol.

\section{DISCUSSION}

$\mathrm{Bu}_{2} \mathrm{AE}$ has been shown to produce convulsions and neuromuscular blockade resulting in respiratory arrest. None of the peripherially acting drugs selected for possible antagonistic action to the neuromuscular blockade produced by $\mathrm{Bu}_{2} \mathrm{AE}$ had any noticeable cffect. Howcver, two centrally acting anticonvulsants were effective in counteracting both the convulsive seizures and the respiratory arrest produced by $\mathrm{Bu}_{2} \mathrm{AE}$. Thus for $\mathrm{Bu}_{2} \mathrm{AE}$ there appears to be a relationship between the primary mechanism 
causing convulsions and the subsequent neuromuscular blockade which results in death due to respiratory arrest.

$\mathrm{Bu}_{2} \mathrm{AE}$ appears to possess a duality in its mode of action. First, it produces a greatly increased CNS activity which results in strong tonic-clonic convulsions. Respiratory arrest due to the neuromuscular blockade develops during this period of elevated CNS activity. Since $\mathrm{Bu}_{2} \mathrm{AE}$ is also a moderate acetylcholinesterase inhibitor, this increased nerve activity with its simultaneous increase in release of acetylcholine at the junction, may result in a neuromuscular blockade due to excess acetylcholine at that site.

\section{ACKNOWLEDGMENTS}

Supported in part by U.S. Public Health Service Grant UI-00482 from the National Center of Urban and Industrial Health. The technical assistance of Mr. Kolman J. Hahn is gratefully acknowledged.

\section{REFERENCES}

Berkson, J. (1944). Application of the logistic function to bio-assay. Am. Stat. Assoc. J. 39, 357-365.

CoRnish, H. H., DambrausKas, T., and BeatTy, L. D. (1969). Oral and inhalation toxicity of 2-N-dibutylaminoethanol. Am. Indust. Hyg. Assoc. J., 30, 46-51.

Gero, A. (1963). Chemical models of drug-receptor interaction II. J. Med. Pharm. Chem. 6, $458-459$.

Hartung, R., and Cornish, H. H. (1968). Cholinesterase inhibition in the acute toxicity of alkyl-substituted 2-aminoethanols. Toxicol. Appl. Pharmacol. 12, 486-494.

Smyth, H. F., Carpenter, C. P., Weil, C. S., and Pozzani, U. C. (1954). Range-finding toxicity data, List V. Arch Indust. Health Occup. Med. 10, 61-68. 